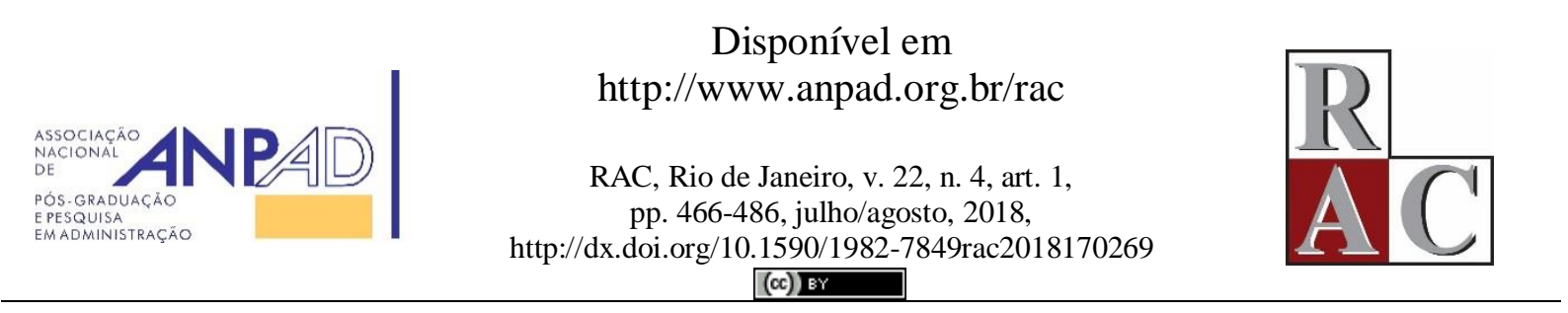

\title{
Eleições Parlamentares no Brasil: O Uso do Twitter na Busca por Votos
}

\author{
Parliamentary Elections in Brazil: The Use of Twitter in the Search for Votes
}

\begin{abstract}
Marcelo Santos Amaral ${ }^{1}$ José Antonio Gomes de Pinho

Universidade Estadual do Sudoeste da Bahia, Departamento de Ciências Sociais Aplicadas, Vitória da Conquista, BA, Brasil ${ }^{1}$ Universidade Federal da Bahia, Escola de Administração, Salvador, BA, Brasil ${ }^{2}$
\end{abstract}

Artigo recebido em 24.08.2017. Última versão recebida em 10.11.2017. Aprovado em 16.06.2018. 


\title{
Resumo
}

Desde o uso das novas tecnologias nas eleições americanas de 2008, o Twitter tem se tornado uma plataforma para as atividades políticas, criando um canal para a interação entre políticos e eleitores. A comunicação política com o uso de mídia social é parte das atividades congressistas nos dias atuais. Além disto, o Twitter se constitui como importante meio para o ganho de popularidade com fins eleitorais. A questão de pesquisa que norteia este artigo é verificar como o comportamento dos parlamentares influencia o uso do Twitter na busca por votos nas eleições ao Congresso Nacional. Assim, o objetivo deste trabalho é analisar os diferentes comportamentos dos políticos brasileiros no ambiente virtual antes, durante e após as eleições parlamentares de 2014. Foram coletadas informações da plataforma do Twitter em quatro momentos, entre dezembro de 2013 e abril de 2015. Os políticos foram comparados segundo suas aspirações eleitorais e conforme as diferentes apropriações da rede social. Os dados indicam que políticos em campanha eleitoral fazem maior e mais frequente uso das novas tecnologias, no sentido de construírem uma imagem política dentro do contexto eleitoral. Como resultado, esses políticos obtiveram maior atenção dos usuários do Twitter, o que está diretamente relacionado a um maior número de votos obtidos no pleito eleitoral.

Palavras-chave: eleições legislativas; redes sociais; Twitter; Congresso Nacional.

\begin{abstract}
Since the use of new technologies in the 2008 US elections, Twitter has become a platform for political activities, creating a channel for interaction between politicians and voters. Political communication with the use of social media is part of today's congressional activities. In addition, Twitter has become an important means for gaining popularity for election purposes. This article's research question is to verify how parliamentarians' behaviors influence the use of Twitter in the search for votes in elections to the National Congress. Thus, the aim of this article is to analyze Brazilian politicians' different behaviors in this virtual environment before, during and after the parliamentary elections of 2014. Data was collected on the use of Twitter by the parliamentarians four times between December 2013 and April 2015. Politicians were compared according to their electoral aspirations and to the different appropriations of the social network. Data indicate that politicians in electoral campaigns make greater and more frequent use of the new technologies, in the sense of constructing political images within the electoral context. As a result, these politicians got more attention from Twitter users, which is directly related to a higher number of votes obtained in the election process.
\end{abstract}

Key words: legislative elections; social networks; Twitter; National Congress.

JEL Classification Codes: L82, L86, D72. 


\section{Introdução}

Desde que o Twitter se tornou uma parte importante da bem-sucedida campanha eleitoral de Barack Obama à presidência dos Estados Unidos, boa parte dos políticos voltaram suas atenções ao uso das novas tecnologias, especialmente das mídias sociais. Da campanha ao parlamento europeu, em 2009, à campanha eleitoral brasileira à presidência, em 2010, o Twitter tem sido cada vez mais usado como meio para promoção da imagem dos políticos em diversos momentos, especialmente durante períodos eleitorais.

No contexto brasileiro, o uso de novas tecnologias deve ser compreendido a partir da compreensão da cultura política existente, que, por um lado, inclui relações clientelistas entre representantes e representados e práticas patrimonialistas de gestão pública, e, por outro, compreende a apatia da população em participar da vida política. O sentimento de que as instituições estão corrompidas e não representam os interesses dos cidadãos pode estar se refletindo na apatia política dos brasileiros, diminuindo as expectativas da promoção da transparência política, da promoção do debate e da deliberação. A política brasileira ainda não é transparente e este é um padrão de realidade que provavelmente está se repetindo nas relações políticas mediadas por computador, como oposto do esperado surgimento de novas práticas mais democráticas de relacionamento entre políticos e cidadãos, conforme o antes descrito potencial democrático da internet.

O legislativo brasileiro, enquanto poder democrático, principal representante dos interesses do povo e relevante indicador político do sistema partidário brasileiro, compreende importante instituição de representação política, e tanto seu funcionamento quanto seu relacionamento com a sociedade reflete, em certa medida, o nível de desenvolvimento do sistema político. Há, no entanto, um quadro de crescente fragmentação partidária no contexto político-partidário brasileiro e, consequentemente, no Congresso Nacional. Essa fragmentação tornou-se mais proeminente a partir da $55^{\mathrm{a}}$ Legislatura (20152018), com o elevado número de partidos representados no Congresso Nacional.

Em princípio, a internet pode criar novas formas de relacionamento, de interação e mesmo de representação política entre o Congresso e os cidadãos. No entanto, o desenvolvimento e a implementação de novas tecnologias de comunicação mostram que, quando o rádio ou a televisão foram adotados, houve uma reprodução dos padrões anteriores de relacionamento político. Apesar de não serem mídias do tipo broadcasting, as novas ferramentas de comunicação e interação da internet não parecem ser suficientemente importantes para promover a mudança na cultura política de políticos e cidadãos.

Neste sentido, mostra-se relevante a investigação sobre a forma como os políticos se apropriam dos novos meios de comunicação via novas Tecnologias da Informação e da Comunicação (TIC). As motivações de diferentes parlamentares podem estar sendo guiadas por diferentes percepções sobre as novas relações políticas nos tempos de internet: se o meio for suficientemente relevante para a projeção da imagem dos políticos na sociedade; se os usuários do Twitter representam ou não uma importante parcela da sociedade; se a atuação do partido político na rede social é percebida pelo eleitor através das discussões no ambiente virtual, essas questões começam ainda a serem entendidas a partir da compreensão do comportamento dos políticos nesse meio, bem como de suas percepções sobre essas possibilidades.

O foco deste trabalho, portanto, é a apropriação para fins políticos que os parlamentares estão fazendo do Twitter no período eleitoral, compreendendo aqui o agente político como o protagonista desta relação e não a tecnologia como capaz de promover per si as mudanças na cultura política brasileira. Desta forma, diferentes apropriações são esperadas por diferentes atores políticos. Assim, esse trabalho se propõe a identificar como tais apropriações estão circunscritas nos limites das curtas mensagens e das conexões realizadas no Twitter, e avaliar como diferentes usos da tecnologia tiveram repercussão nos resultados eleitorais de 2014. 


\section{Referencial Teórico}

O uso cada vez mais frequente das novas tecnologias tem alterado as formas de conexão, a troca de informações e os comportamentos dos cidadãos e organizações. Essas mudanças não poderiam deixar de alterar a forma com que a sociedade política utiliza os canais de comunicação para interagir com os cidadãos. No caso das mídias sociais, alguns estudos já demonstram o movimento de adesão de políticos, gestores públicos e governos às novas TIC, em resposta ao forte movimento de adesão a essas tecnologias por parte dos eleitores. Os políticos podem estar apenas buscando visibilidade, popularidade e apoio a suas carreiras políticas, ou podem também buscar o diálogo com eleitores, responder a questionamentos e prestar contas de seus mandatos.

No contexto brasileiro, o uso de novas tecnologias deve ser compreendido a partir da cultura política existente, que inclui relações clientelistas entre representantes e representados e práticas patrimonialistas de gestão pública (Pinho, 2016), como também o sentimento do cidadão brasileiro de indiferença ou apatia em relação à política. O Brasil tem sido apontado como uma sociedade que mistura componentes da modernidade e do atraso. Dentre os problemas da política brasileira, Marco Aurélio Nogueira identificou apatia nos cidadãos, inoperância e falta de desprendimento dos políticos (Nogueira, 1998). Para o autor, apesar da modernização ocorrida nos últimos tempos, não houve avanços correspondentes no campo das instituições políticas, com a sociedade civil despolitizada e sem funcionar, de modo regular e eficaz, como contrapeso ao Estado.

Para Oliveira, Catapan e Vicentín (2015), a legitimação do poder do Estado pelo povo se dá pela escolha de seus representantes, através do processo eleitoral. No entanto, o sentimento de abandono e a falta de esperanças em relação a esses mesmos representantes levam os eleitores a uma predisposição à apatia ou a relações clientelistas, personalistas e patrimonialistas. A partir de uma análise do nível de participação dos cidadãos no percurso eleitoral e da constatação do desinteresse em decidir, por instrumentos como votos nulos/brancos ou abstendo-se, Oliveira et al. (2015) avaliaram que há mesmo um nível elevado de apatia na sociedade brasileira, sentimento esse que possui "causas difíceis de serem mensuradas" (p. 121). Ainda que se possa argumentar que nem todo voto nulo representa uma posição de apatia ou indiferença ao processo eleitoral, há, de fato, um sentimento de indiferença pela maior parte da sociedade brasileira em relação a seus representantes.

Exemplo de nova ferramenta de comunicação e interação, o Twitter foi lançado em 2006 inicialmente como serviço de microblogging para postagens de situações cotidianas, tornando-se depois um meio de comunicação para todo e qualquer tópico de discussão, como notícias jornalísticas ou políticas, frases e citações, links para websites, e, em tempos de eleições, especificamente para as discussões políticas que dominam os principais assuntos discutidos nessa rede (Tumasjan, Sprenger, Sandner, \& Welpe, 2010). O Twitter é uma ferramenta de comunicação que possibilita a seus usuários a descrição de sua atual situação ou Status através de mensagens curtas - tweets - publicadas por suas contas ou perfis (Java, Finin, Song, \& Tseng, 2007). Esta foi a característica que distinguiu e ainda distingue o Twitter de outras mídias sociais - a limitação do tamanho do conteúdo a ser compartilhado, em 140 caracteres de texto.

Desde 2008, quando o então candidato à presidência dos Estados Unidos, Barack Obama, utilizou as redes sociais da internet como parte de sua estratégia de campanha (Braga \& Cruz, 2012; Gomes, Fernandes, Reis, \& Silva, 2009; Williams \& Spiro, 2015), muitos políticos passaram a considerar importantes esses recursos de comunicação, desde o uso relutante pelos candidatos ao parlamento europeu em 2009 (Vergeer, Hermans, \& Sams, 2013), à novidade eleitoral brasileira da candidata à presidência pelo Partido Verde em 2010 (Costa, 2011; Pereira, 2013; Reis, 2011). Como uma das mais conhecidas redes sociais da internet, o Twitter passou a ser considerado um recurso disponível e acessível a muitos políticos em sua comunicação política e, principalmente, em suas estratégias eleitorais. Mesmo ainda não tendo sido avaliados o debate e a extensão do uso político desse meio, há comunicação e deliberação política no ambiente virtual (Tumasjan et al., 2010). 
Três anos após a criação do Twitter, Java, Finin, Song e Tseng (2007), ao analisarem os motivos da adoção desse microblogging, concluíram que havia três principais grupos de usuários no Twitter: os usuários populares e bastante ativos; os usuários pouco populares, buscando informações, mas produzindo pouco conteúdo; e os usuários que estavam conectados com amigos, família ou rede de relacionamentos profissionais. Analisando as redes em torno das contas mais populares, além de identificarem esses diferentes grupos de usuários, os autores também encontraram diferentes padrões de conexão, concluindo que os usuários tendem a participar e a compartilhar informações em grupos que partilham de mesmos interesses (Java et al., 2007). O movimento de aproximação social aqui vai mais no sentido dos interesses dos usuários e menos no sentido de adesão formal a uma causa ou filiação a um grupo.

Um dos aspectos sobre o uso das redes sociais da internet diz respeito à influência exercida por alguns usuários sobre outros. No Twitter, essa questão se refere à possibilidade de um elevado número de seguidores representar ou não, para a pessoa ou organização seguida, algum poder de influência sobre outros usuários. A popularidade virtual pode representar prestígio, fama e Status ao usuário de uma conta excepcionalmente seguida na rede social, como pode apenas replicar o Status social anterior à existência do perfil virtual. Cha, Haddadi, Benevenuto e Gummadi (2010) coletaram grande quantidade de dados sobre o uso do Twitter em 2009 e avaliaram a influência que uns usuários podem estar exercendo sobre os outros, de acordo com três categorias: número de conexões de entrada; número de vezes que as mensagens de um usuário foram repassadas por outros usuários a seus respectivos seguidores; e número de vezes que o nome único do perfil de um usuário foi citado por outros usuários em suas mensagens.

Cha et al. (2010) afirmam que usuários populares não são necessariamente os mais influentes, enquanto aqueles realmente mais influentes conseguem manter essa característica mesmo sobre uma diversidade de tópicos discutidos no ambiente virtual. Tal influência não é conquistada de forma espontânea ou acidental, mas através de esforço direcionado do usuário no sentido de especializar sua atuação na rede em um único tópico, postando mensagens relevantes e criativas (Cha, Haddadi, Benevenuto, \& Gummadi, 2010). Assim, enquanto Java et al. (2007) concluíram haver espontaneidade dos usuários comuns na formação de redes de conexões através de interesses coincidentes, o trabalho de Cha et al. (2010) identifica que há um esforço direcionado por parte de alguns usuários do Twitter para obter influência na rede, e esse esforço redunda em popularidade no meio.

Mesmo com os baixos custos na adoção do uso do Twitter, um político corre o risco de ter sua imagem associada a um fracasso de popularidade ou de ver revelado o fraco apoio que suas ideias podem ter na sociedade (Chi \& Yang, 2011). Mas o sucesso obtido pelos políticos early adopters pode incentivar outros a adotarem novas ferramentas para promoção de suas imagens e ideias. Neste sentido, Chi e Yang (2011) observaram que os políticos americanos adotaram mais rapidamente o uso do Twitter a partir dos sinais de sucesso observados por eles no uso pioneiro do Twitter por outros políticos. De forma geral, os parlamentares americanos se sentiam pressionados a competir por atenção contra seus competidores quando observavam o sucesso que estes estavam obtendo no uso do Twitter (Chi \& Yang, 2011).

Tumasjan, Sprenger, Sandner e Welpe (2010) analisaram o uso da plataforma do Twitter no contexto das eleições alemãs, buscando compreender: (a) a possibilidade desta ser um meio para deliberação política; (b) a capacidade de reflexão das mensagens publicadas nessa rede refletirem o sentimento político contemporâneo de fora do ambiente virtual; e (c) a possibilidade da atividade das contas no Twitter poder ser usada para predizer ou estimar a popularidade dos partidos ou das coligações políticas. Os autores concluíram que, apesar de os dados sobre interação e comunicação demonstrarem que o Twitter estava sendo usado como um fórum para a deliberação política, este fórum ainda era dominado por um número pequeno de usuários muito influentes e que postavam bem mais mensagens do que os usuários comuns (Tumasjan et al., 2010).

A similaridade encontrada entre os perfis dos candidatos no ambiente on-line refletia as muitas nuances dos debates e a dinâmica da campanha eleitoral alemã, também refletindo o sentimento político contemporâneo de seu eleitor no ambiente off-line, enquanto as mensagens postadas pelos usuários no 
período imediatamente anterior às eleições apontavam adequadamente o resultado posterior do pleito (Tumasjan et al., 2010). Vale indicar que havia uma relação entre o conjunto das discussões on-line e os votos obtidos pelos candidatos ao parlamento alemão. Os autores concluíram que o Twitter estava, naquele contexto, sendo usado extensivamente para a deliberação pública, e que havia correlação entre o número de mensagens na plataforma que mencionaram determinado partido e o resultado desse partido nas eleições na Alemanha (Tumasjan et al., 2010).

Um dos estudos mais abrangentes sobre o uso do Twitter por parlamentares foi realizado por Golbeck, Grimes e Rogers (2010). Os autores analisaram as mensagens postadas no Twitter por membros do congresso americano para compreender como eles estariam se comunicando através dessa rede social e que tipo de conteúdo eles estariam postando no ambiente virtual. Para compreender a evolução no uso da ferramenta pelos políticos, os autores coletaram e codificaram as últimas mensagens dos congressistas americanos em três diferentes momentos: fevereiro, junho e agosto de 2009. As categorias utilizadas compreendiam a comunicação direta do político com um usuário específico, mensagens pessoais não relacionadas ao mandato, mensagens informativas sobre o trabalho dos parlamentares, apelos para arrecadação de fundos ou doações, dentre outras. Os autores concluíram que a maior parte das mensagens postadas pelos políticos americanos eram apenas informativas (Golbeck et al., 2010).

Os resultados do trabalho de pesquisa de Golbeck et al. (2010) são bem semelhantes a conclusões de estudos similares realizados em outros países, tanto em relação à frequência do uso da rede quanto ao conteúdo postado no Twitter pelos políticos. Apesar do potencial do Twitter para viabilizar o debate on-line, os autores concluíram que o fórum do Twitter não estava sendo usado para novas formas de comunicação entre os congressistas e seus eleitores. Hemphill, Otterbacher e Shapiro (2013) também buscaram descrever o comportamento dos congressistas americanos, através da análise dos conteúdos das mensagens postadas por eles no Twitter. Usando uma metodologia de classificação automática dos textos publicados pelas contas dos parlamentares americanos e corroborando as análises de Goldbeck et al. (2010), os autores concluíram que os políticos usavam o Twitter frequentemente para dar publicidade às suas posições políticas e para divulgar informações, mas raramente para mobilizar seus eleitores ou para reconhecer o trabalho de outros parlamentares (Hemphill, Otterbacher, \& Shapiro, 2013).

As pesquisas iniciais sobre o uso do Twitter realizadas em outros países e citadas anteriormente apontaram para a confirmação da previsão de alguns críticos da internet de que esse meio não seria capaz de promover mudanças estruturais nas relações políticas que viria a mediar. Estudos similares foram também realizados no Brasil, como se descreve na seção a seguir.

\section{Twitter e Campanha Política no Brasil}

No Brasil, Marques e Sampaio (2011) analisaram a interação entre usuários das redes sociais e a campanha política à presidência do Brasil em 2010. Para os autores, é possível observar o uso cada vez maior da rede mundial de computadores para difusão de informações, tanto por políticos em campanha eleitoral como pelos usuários da rede. $\mathrm{O}$ uso da internet para promoção de campanhas tem se tornado cada vez mais complexo, à medida em que cresce a exigência por informação e interação pelos usuários das redes sociais. Porém, por conta da natureza da utilização das redes, não está claro se são os próprios políticos os reais usuários da ferramenta (Marques \& Sampaio, 2011).

Para os autores, o uso político da internet tem aumentado consideravelmente, especialmente nos períodos de campanhas eleitorais, variando da simples criação de sites estáticos e meramente informativos a páginas incrementadas de recursos audiovisuais, chegando recentemente ao uso das redes sociais para aproximação das coordenações de campanha aos eleitores e à tentativa de formação de opinião por esse meio. Duas características são apontadas pelos autores para os modelos de oferta e consumo de informações políticas da última campanha presidencial no Brasil: há uma maior disponibilidade de informações geradas tanto por candidatos e partidos políticos quanto pelos eleitores 
usuários; há uma maior concorrência entre as campanhas eleitorais pela atenção dos usuários na rede (Marques \& Sampaio, 2011).

As mídias sociais desempenharam um papel complementar às ações dos candidatos à presidência do Brasil em 2010 (Marques \& Sampaio, 2011). A repercussão de fatos políticos nas redes pautou parte das discussões on-line durante a campanha eleitoral, levando à cobertura pela imprensa da repercussão dessas discussões dentro das redes. Um fato ou tema que era noticiado pelos meios de comunicação de massa ou pelos grandes sites de notícias da internet poderia rapidamente entrar na lista de assuntos mais discutidos do Twitter, voltando à pauta jornalística. Assim, "o Twitter se revelou, nas eleições de 2010, como uma rede de ligação que une outras diferentes redes existentes na internet e que pouco se tocavam" (Marques \& Sampaio, 2011, p. 214). As redes sociais viabilizaram também a distribuição de conteúdos entre usuários, tanto para o bem quanto para o mal, e a impossibilidade de controle das discussões nas redes levou candidatos a serem confrontados com assuntos indesejados e a se verem impelidos a responder questões polêmicas, com potencial de perda de votos.

Natasha Pereira (2013) analisou também o uso político do Twitter pelos quatro principais candidatos à presidência, na campanha eleitoral de 2010. O estudo buscou descrever a imagem que cada candidato construiu no ambiente virtual, sua interação com eleitores e com os outros candidatos, e as possibilidades do uso das redes sociais para a promoção do debate e da participação, especialmente durante o período eleitoral. As conclusões apontam para a reafirmação do personalismo político brasileiro, com os dados demonstrando que há um apelo dos políticos à subjetividade dos eleitores, com postagens de mensagens pessoais, congratulações e agradecimentos, perpetuando a "lógica dual da política no sentido de permitir a exploração tanto de sua faceta subjetiva quanto da racional" (Pereira, 2013, p. 217).

A despeito do tom personalista das mensagens postadas pelos políticos presidenciáveis em 2010, o trabalho de Natasha Pereira identificou também uma certa aproximação entre representantes e representados, já que a participação política via Twitter colaborou para a formação de uma agenda setting entre o meio digital e os meios de comunicação de massa (Pereira, 2013), o que pode indicar certa influência das redes sociais da internet sobre a opinião pública, ainda que de forma indireta e restrita a uma parcela da sociedade.

Marques, Aquino e Miola (2014) analisaram porque os parlamentares brasileiros escolheram usar o Twitter como parte de suas estratégias políticas de comunicação. Os autores enumeraram aspectos individuais relacionados ao uso do Twitter pelos deputados federais em fevereiro de 2013. Nessa pesquisa, a ideologia dos partidos e dos parlamentares foi relacionada ao uso do Twitter, à frequência de mensagens postadas e ao número de usuários seguidores do perfil de cada parlamentar. Os autores avaliaram as relações entre estas informações a variáveis independentes, como posição de liderança no Congresso, quantidade de votos recebidos nas últimas eleições e perfil socioeconômico dos eleitores, concluindo que políticos de partidos de esquerda tinham mais seguidores e usavam mais o Twitter.

Ainda segundo os dados da pesquisa de Marques et al. (2014), parlamentares iniciantes e/ou mais jovens usavam mais intensamente o Twitter, enquanto políticos eleitos com mais votos, assim como também aqueles que possuíam conta no Twitter há mais tempo, tinham mais seguidores que a média das contas analisadas (Marques, Aquino, \& Miola, 2014). Essas conclusões foram depois corroboradas pelas análises de Amaral e Pinho (2015), que utilizaram dados sobre o uso do Twitter pelos políticos brasileiros em 2013.

O tema do uso político das redes sociais é ainda muito recente na literatura, especialmente no Brasil. Porém, muito do diagnóstico sobre o comportamento dos políticos e sobre o sistema partidário do ambiente off-line já tem sido confirmado no ambiente virtual, mesmo nos estudos iniciais citados anteriormente. $\mathrm{O}$ padrão de apropriação da tecnologia pelos parlamentares não deve diferir daquele que se poderia esperar, dado o quadro político brasileiro no contexto de sua cultura política e a partir dos estudos que relacionaram política ao uso político das novas tecnologias. Se, por um lado, os cidadãos mostram-se, de uma forma geral, historicamente apáticos e avessos ao debate político no Brasil, por outro, o uso das redes sociais tem sido amplamente difundido no país, e os impactos desse uso nas 
relações políticas pode ser avaliado a partir de uma análise do comportamento dos políticos em reação à mudança nos hábitos de comunicação e interação da sociedade.

\section{Metodologia}

O objetivo deste trabalho é analisar as diferentes apropriações do Twitter pelos parlamentares brasileiros, antes, durante e após o período eleitoral, e como esse uso está relacionado ao resultado eleitoral obtido pelos políticos. Assim, o problema desta pesquisa relacionou os parlamentares e o uso do Twitter, tendo como referência de análise suas aspirações eleitorais: Como os parlamentares, Deputados e Senadores, utilizaram o Twitter durante o período eleitoral de 2014, dadas suas pretensões políticas, e como esses diferentes usos resultaram em diferentes resultados políticos.

O Twitter é uma plataforma para redes sociais que se distingue por permitir somente a publicação de textos curtos - tweets ou mensagens com, no máximo, 140 caracteres $^{(1)}$. Os usuários das contas ou perfis da plataforma podem: (a) postar mensagens com links para outras páginas da internet ou conteúdos multimídia (imagens ou vídeos); (b) podem repetir mensagens postadas por outros usuários (chamados de retweets); (c) citar outros perfis em suas mensagens (menções); e (d) podem estabelecer conexões entre si - um perfil A pode ser um seguidor do perfil B, o que torna A um follower de B, e B, um following de A; se B também escolher seguir A, então a conexão se torna recíproca. As contas do Twitter apresentam as quantidades de perfis seguidores e seguidos de cada usuário, assim como a data de sua criação e os registros das postagens dos usuários.

Os dados analisados neste trabalho foram coletados de forma automatizada através da Application Programming Interface (API) do Twitter - uma interface de programação para aplicativos, programas e websites, que podem prover serviços com os dados e os recursos do Twitter, mas que também pode ser utilizada para a coleta de dados neste ambiente. Após a validação da relação das contas parlamentares, a coleta dos dados foi realizada em quatro momentos distintos: (a) sete meses antes do início do período eleitoral, em 20 de dezembro de 2013; (b) no início oficial da campanha eleitoral de 2014, em 31 de julho de 2014; (c) no ápice desta campanha, em 30 de setembro de 2014; e (d) sete meses após as eleições, em 30 de abril de 2015.

Os seguintes dados foram coletados em cada etapa: a data de criação das contas parlamentares no Twitter, o total de seus seguidores, o total de perfis seguidos, o total de mensagens postadas e a data da última mensagem postada. A relação das contas parlamentares foi validada e complementada com buscas na própria plataforma da mídia social e as relações oficiais e atualizadas dos parlamentares em exercício no momento de cada etapa foram obtidas nos websites da Câmara dos Deputados (http://www.camara.gov.br) e do Senado Federal (http://www.senado.gov.br), complementadas com dados obtidos em sites institucionais do Congresso Nacional e em outros bancos de dados, como o site Políticos do Brasil, mantido pelo portal UOL Notícias (http://noticias.uol.com.br/politica/politicosbrasil).

Dentre os 513 Deputados e os 81 Senadores que compõem o Congresso Nacional, muitos políticos eleitos encontravam-se afastados do exercício de seus mandatos nos momentos de coleta dos dados. Assim, os nomes dos políticos suplentes em exercício compuseram a lista dos parlamentares analisados em cada etapa de coleta e análise. O total de políticos analisados neste estudo compreendeu os 594 congressistas em exercício em dezembro de 2014, somados a outros 49 políticos incluídos na segunda e na terceira etapas e os 252 novos parlamentares eleitos em 2014. Outros dois parlamentares titulares estavam ausentes nas três primeiras etapas e voltaram ao exercício de seus mandatos em abril de 2015, totalizando 897 políticos analisados neste trabalho. De acordo com a intenção do político em concorrer ou não às eleições de 2014, e de acordo com o cargo pretendido, os 897 congressistas foram divididos nos oito seguintes grupos de análise: 
Candidatos reeleitos: parlamentares que tentaram e conseguiram se reeleger para o mesmo cargo no legislativo federal;

Candidatos não reeleitos: parlamentares que tentaram e não conseguiram a reeleição para o cargo que ocupavam na $54^{a}$ legislatura;

Candidatos a outros cargos: Deputados e Senadores que se candidataram a outros cargos e que, eleitos ou não, deixaram o Congresso Nacional;

Não candidatos: Deputados ou Senadores em fim de mandato que não se candidataram a qualquer cargo eletivo em 2014 e que, por isto, saíram do Congresso;

Novos parlamentares: novos Deputados e Senadores da $55^{a}$ Legislatura que não haviam ocupado qualquer cargo no Congresso Nacional em quaisquer das três primeiras etapas de análise;

Senadores candidatos que permaneceram: políticos em meio de mandato, que se candidataram a um cargo eletivo e perderam a eleição, mas continuaram no Senado;

Senadores não candidatos que permaneceram: Senadores em meio de mandato que não se candidataram nas eleições de 2014 e permaneceram no Senado;

Candidatos que trocaram de cargo: Deputados Federais que se elegeram Senadores e os Senadores que se elegeram Deputados Federais nas eleições de 2014.

A Tabela 1 relaciona e quantifica os oito grupos acima descritos, conforme sexo, idade, presença no Twitter e o cargo que ocupavam em setembro de 2014 e, para os novos congressistas, em abril de 2015:

Tabela 1

Atividade das Contas Parlamentares Durante e Após as Eleições, por Status Eleitoral do Político

\begin{tabular}{|c|c|c|c|c|c|c|c|}
\hline \multirow{2}{*}{ Status eleitoral do parlamentar } & \multicolumn{2}{|c|}{ Cargo } & \multicolumn{2}{|c|}{ Tem Twitter? } & \multicolumn{2}{|l|}{ Sexo } & \multirow{2}{*}{$\begin{array}{l}\text { Média de } \\
\text { Idade }\end{array}$} \\
\hline & Dep. & Sen. & Não & Sim & Mas. & Fem. & \\
\hline $\begin{array}{l}\text { Candidatos à reeleição que foram } \\
\text { reeleitos. }\end{array}$ & 285 & 5 & 25 & 266 & 267 & 23 & 54,5 \\
\hline $\begin{array}{l}\text { Candidatos à reeleição que não foram } \\
\text { reeleitos. }\end{array}$ & 119 & 4 & 12 & 111 & 112 & 11 & 60,0 \\
\hline $\begin{array}{l}\text { Candidatos a outros cargos que saíram } \\
\text { do Congresso. }\end{array}$ & 70 & 11 & 14 & 67 & 70 & 11 & 56,3 \\
\hline $\begin{array}{l}\text { Não candidatos que saíram do } \\
\text { Congresso. }\end{array}$ & 72 & 19 & 30 & 61 & 85 & 6 & 61,7 \\
\hline Novos parlamentares & 230 & 22 & 40 & 212 & 219 & 33 & 49,2 \\
\hline $\begin{array}{l}\text { Senadores candidatos que permaneceram } \\
\text { no Senado. }\end{array}$ & - & 15 & 1 & 14 & 11 & 4 & 59,8 \\
\hline $\begin{array}{l}\text { Senadores não candidatos que } \\
\text { permaneceram no Senado. }\end{array}$ & - & 35 & 1 & 34 & 33 & 2 & 61,5 \\
\hline $\begin{array}{l}\text { Parlamentares eleitos que trocaram de } \\
\text { cargo no Congresso. }\end{array}$ & 7 & 3 & 2 & 8 & 9 & 1 & 53,0 \\
\hline
\end{tabular}

Nota. Dados coletados em 30 de setembro de 2014 e 30 de abril de 2015. Fonte: Elaborada pelo autor.

Foram comparados os indicadores de uso do Twitter dos diferentes grupos de parlamentares descritos acima através de suas médias, sendo aplicado, nessa comparação, o método de correção de Bonferroni aos ajustes dos intervalos de confiança, que considera os desvios dos valores em torno da 
média. Foram comparadas também a evolução das proporções ao longo dos quatro períodos de análise. Para os valores não paramétricos, com distribuição não normal, foi aplicada a Correlação de Postos de Spearman, que compara a classificação de duas variáveis para avaliar relações lineares ou não.

\section{Resultados}

Considerando o uso do Twitter pelos parlamentares em exercício em cada etapa de análise, a adesão à ferramenta ficou em cerca de $86 \%$, variando bem pouco esse percentual entre a primeira e a última etapas de coleta de dados. A Figura 1 representa as variações nos percentuais de contas ativas, contas inativas ${ }^{(2)}$ e parlamentares sem conta no Twitter para o período de estudo.

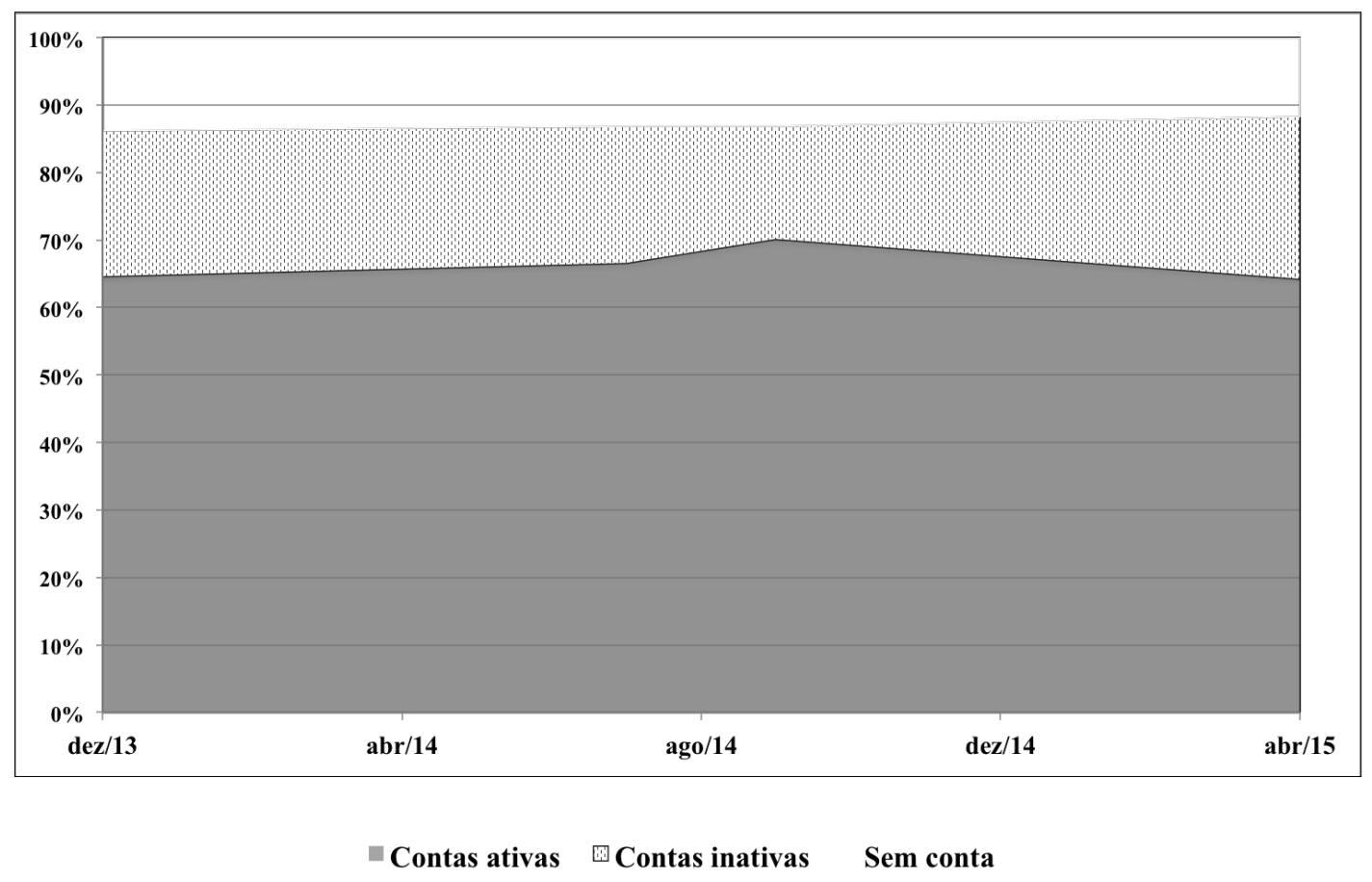

Figura 1. Evolução Percentual de Contas Ativas, Contas Inativas e Parlamentares Sem Conta no Twitter Dados coletados entre 20 de dezembro de 2013 e 30 de abril de 2015. O percentual se refere ao total de 594 parlamentares em exercício em cada etapa da coleta de dados. Fonte: Elaborada pelo autor.

Houve uma pequena variação positiva nas contas ativas na terceira etapa, que corresponde ao período eleitoral, e uma leve diminuição no percentual de parlamentares com conta inativa nesse mesmo período. O percentual de políticos sem conta no Twitter permaneceu praticamente inalterado nas quatro etapas deste estudo, sugerindo um nível de saturação na adoção da tecnologia por parte dos congressistas brasileiros, ou seja, durante os 16 meses entre as quatro etapas de análise, uma parcela dos políticos não aderiu nem pareceu querer aderir ao uso da tecnologia. Essa conclusão sobre a estagnação na adesão ao uso do Twitter é corroborada quando se leva em conta a renovação das cadeiras no Congresso, após as eleições de 2014: a chegada dos novos políticos - cerca de $43 \%$ do total de congressistas - não alterou o percentual de adesão observado nas três etapas anteriores.

O movimento de adesão ao Twitter pelos congressistas analisados aqui está diretamente relacionado à proximidade do período eleitoral de 2010. Até o final de julho de 2010 , cerca de $62 \%$ dos parlamentares já havia criado conta na plataforma (Figura 2). 


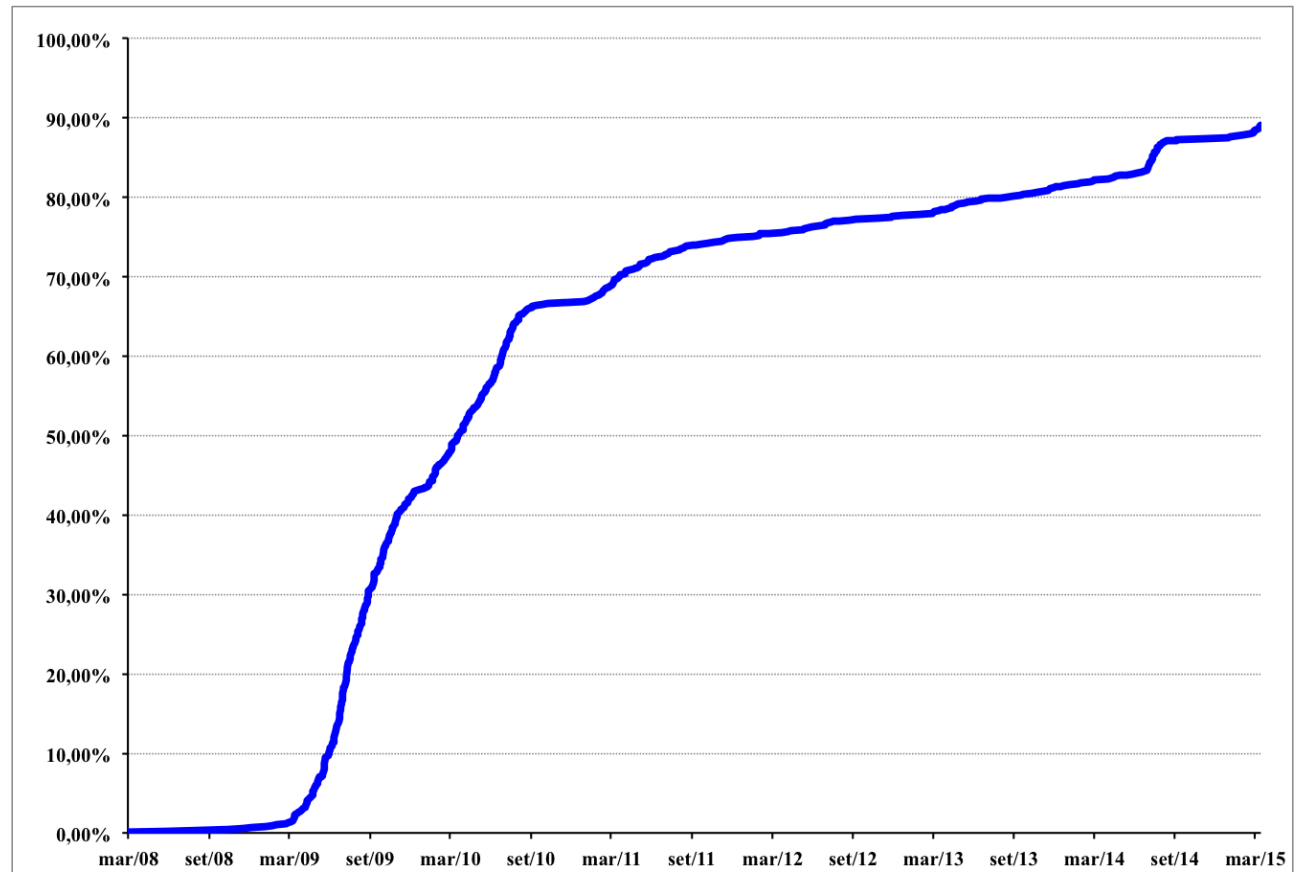

Figura 2. Percentual de Adesão ao Twitter pelos Parlamentares Brasileiros entre 2008 e 2015 Dados coletados entre 20 de dezembro de 2013 e 30 de abril de 2015. O percentual refere-se aos 897 políticos analisados neste trabalho, presentes em ao menos uma etapa de coleta de dados. Fonte: Elaborada pelo autor.

O ritmo de criação de novas contas diminuiu sensivelmente após as eleições de 2010, havendo novo movimento de adesão por parlamentares ainda não conectados às vésperas das eleições de 2014 . A linha da Figura 2 indica que (a) o movimento de adesão ao Twitter foi quase coordenado ou sincronizado em 2009 e que (b) há uma sensível resposta de adesão à tecnologia com a proximidade dos períodos eleitorais. A Tabela 2 compara os percentuais de contas ativas e inativas nos diferentes grupos de análise entre o fim das eleições e o início do novo mandato. O nível de atividade no Twitter pelos grupos com pretensões eleitorais é bem superior ao dos políticos que não concorrem às eleições de 2014 .

Tabela 2

Atividade das Contas Durante e Após as Eleições, por Status Eleitoral dos Parlamentares

\begin{tabular}{lllll}
\hline \multirow{2}{*}{ Status eleitoral dos parlamentares } & \multicolumn{2}{l}{ Contas Ativas (\%) } & \multicolumn{2}{l}{ Contas Inativas (\%) } \\
\cline { 2 - 5 } & Eleições & Pós-Eleições & Eleições & Pós-Eleições \\
\hline Candidatos à reeleição que foram reeleitos. & $69,6 \%$ & $63,1 \%$ & $21,1 \%$ & $28,3 \%$ \\
\hline $\begin{array}{l}\text { Candidatos à reeleição que não foram reeleitos. } \\
\text { Candidatos a outros cargos que saíram do }\end{array}$ & $60,7 \%$ & $35,0 \%$ & $29,9 \%$ & $55,3 \%$ \\
$\begin{array}{l}\text { Congresso. } \\
\text { Não candidatos que saíram do Congresso. }\end{array}$ & $36,9 \%$ & $45,7 \%$ & $11,2 \%$ & $37,0 \%$ \\
\hline $\begin{array}{l}\text { Senadores candidatos que permaneceram no } \\
\text { Senado. }\end{array}$ & $86,7 \%$ & $80,0 \%$ & $0,0 \%$ & $13,3 \%$ \\
\hline $\begin{array}{l}\text { Senadores não candidatos que permaneceram } \\
\text { no Senado. }\end{array}$ & $71,4 \%$ & $82,9 \%$ & $17,9 \%$ & $14,3 \%$ \\
\hline $\begin{array}{l}\text { Parlamentares eleitos que trocaram de cargo no } \\
\text { Congresso. }\end{array}$ & $55,6 \%$ & $80,0 \%$ & $22,2 \%$ & $0,0 \%$ \\
\hline
\end{tabular}

Nota. Dados coletados em 30 de setembro de 2014 e 30 de abril de 2015. Fonte: Elaborada pelo autor. 
Comparando os dois grupos da Tabela 2 que não concorrem a qualquer cargo nas eleições, os políticos em meio de mandato marcaram maior presença no ambiente virtual em relação aos parlamentares que saíram do Congresso, o que indica que a indiferença ao uso da tecnologia está diretamente relacionada à pouca perspectiva política de curto prazo no primeiro grupo. Outro ponto a ser observado é que, mesmo entre os grupos mais ativos no Twitter, houve uma queda na presença dos políticos nessa rede após as eleições, exceto nos dois últimos grupos da Tabela 2, enquanto os políticos que perderam as eleições ou que não se candidataram se afastaram ainda mais do uso dessa rede social após o período eleitoral, abandonando suas contas ou mesmo as encerrando.

A Tabela 3 agrupa os parlamentares em dois grupos, de acordo com suas pretensões eleitorais políticos candidatos e políticos não candidatos nas eleições de 2014 - e compara seus indicadores de uso do Twitter em setembro de 2014. O primeiro grupo inclui Deputados e Senadores candidatos à reeleição ou a outro cargo, dentro ou fora do Congresso, enquanto o segundo grupo inclui os parlamentares que não se candidataram a qualquer cargo eletivo. As médias dos totais de seguidores, de mensagens postadas e de contas seguidas não apresentaram diferença significativa entre os grupos. Porém, os dados indicam que a média diária de postagem de novas mensagens entre 31 de julho e 30 de setembro foi bem maior para políticos com pretensões no pleito de 2014 do que para aqueles alheios aos movimentos da campanha eleitoral. Esse nível maior de atividade no período redundou em maior crescimento na popularidade do primeiro grupo, ainda que não tenha havido diferença estatisticamente relevante nesse indicador.

Tabela 3

Indicadores de Uso do Twitter por Parlamentares Candidatos ou Não às Eleições de 2014

\begin{tabular}{lll}
\hline \multirow{2}{*}{ Indicador de uso do Twitter } & \multicolumn{2}{l}{ Candidato nas eleições de 2014 } \\
\cline { 2 - 3 } & $\begin{array}{l}\text { Sim } \\
(\mathrm{N}=463)\end{array}$ & $\begin{array}{l}\text { Não } \\
(\mathrm{N}=128)\end{array}$ \\
\hline Total de Seguidores & $\mathbf{1 3 . 9 8 4}$ & $\mathbf{1 4 . 7 2 1}$ \\
& $(4.398)$ & $(5.780)$ \\
\hline Total de Mensagens Postadas & $\mathbf{6 . 1 1 1}$ & $\mathbf{4 . 8 8 1}$ \\
& $(469)$ & $(806)$ \\
\hline Total de Contas Seguidas & $\mathbf{1 . 4 7 0}$ & $\mathbf{1 . 4 5 8}$ \\
& $(200)$ & $(308)$ \\
\hline Quantidade de dias da Última Postagem & $\mathbf{1 4 1}$ & $\mathbf{2 2 4}$ \\
& $(18)$ & $(50)$ \\
Tempo de Conta (em Anos) & $\mathbf{4 , 5 5}$ & $\mathbf{4 , 5 2}$ \\
& $(0,05)$ & $(0,13)$ \\
Média diária de postagem & $\mathbf{4 , 7 2 * *}$ & $\mathbf{1 , 6 6}$ \\
& $(0,42)$ & $(0,62)$ \\
\hline Crescimento no Número de Seguidores & $\mathbf{5 , 6 6 \%}$ & $\mathbf{2 , 4 9 \%}$ \\
& $(0,85 \%)$ & $(1,34 \%)$ \\
\hline
\end{tabular}

Nota. Valores entre parênteses correspondem ao Erro Padrão da Média. Fonte: Elaborada pelo autor. $\mathrm{O}$ símbolo * indica que a variável é significante a $5 \%(\mathrm{p}<0,05)$, e $* *$, a $1 \%(\mathrm{p}<0,01)$.

Apesar da grande variação nos indicadores para o conjunto dos dados analisados, é possível se afirmar que, no período mais intenso das eleições, o Twitter foi usado intencionalmente pelos parlamentares para dar visibilidade a suas campanhas políticas. Esse padrão de uso do Twitter pelos parlamentares durante o processo eleitoral corrobora estudos anteriores, quando afirmam que, dadas as 
campanhas políticas individualistas e personalistas associadas à baixa institucionalização dos partidos políticos, a habilidade dos candidatos em elaborar uma imagem favorável é politicamente importante (Mainwaring, 2001/2001; Teixeira, 2004), e os políticos, cientes dessa realidade, empenham-se para formar tal imagem através de todos os meios disponíveis. Durante as eleições, os dados indicam que os políticos usam o Twitter como um palanque eleitoral e/ou um canal de divulgação de suas campanhas.

Os dados da Tabela 3 apontam para a diferença entre o ritmo de postagem dos políticos durante o período eleitoral. A relação entre o período das eleições e o ritmo de postagem dos grupos também pode ser visualizada na Figura 3, que apresenta a evolução das médias diárias de postagem nos quatro períodos de análise deste estudo para os parlamentares com conta no Twitter. O valor para o período antes das eleições compreende a média diária de postagem entre a data de criação da conta e o dia 20 de dezembro de 2013, enquanto os outros três períodos seguintes correspondem à média diária de postagem no intervalo entre as datas de coleta.

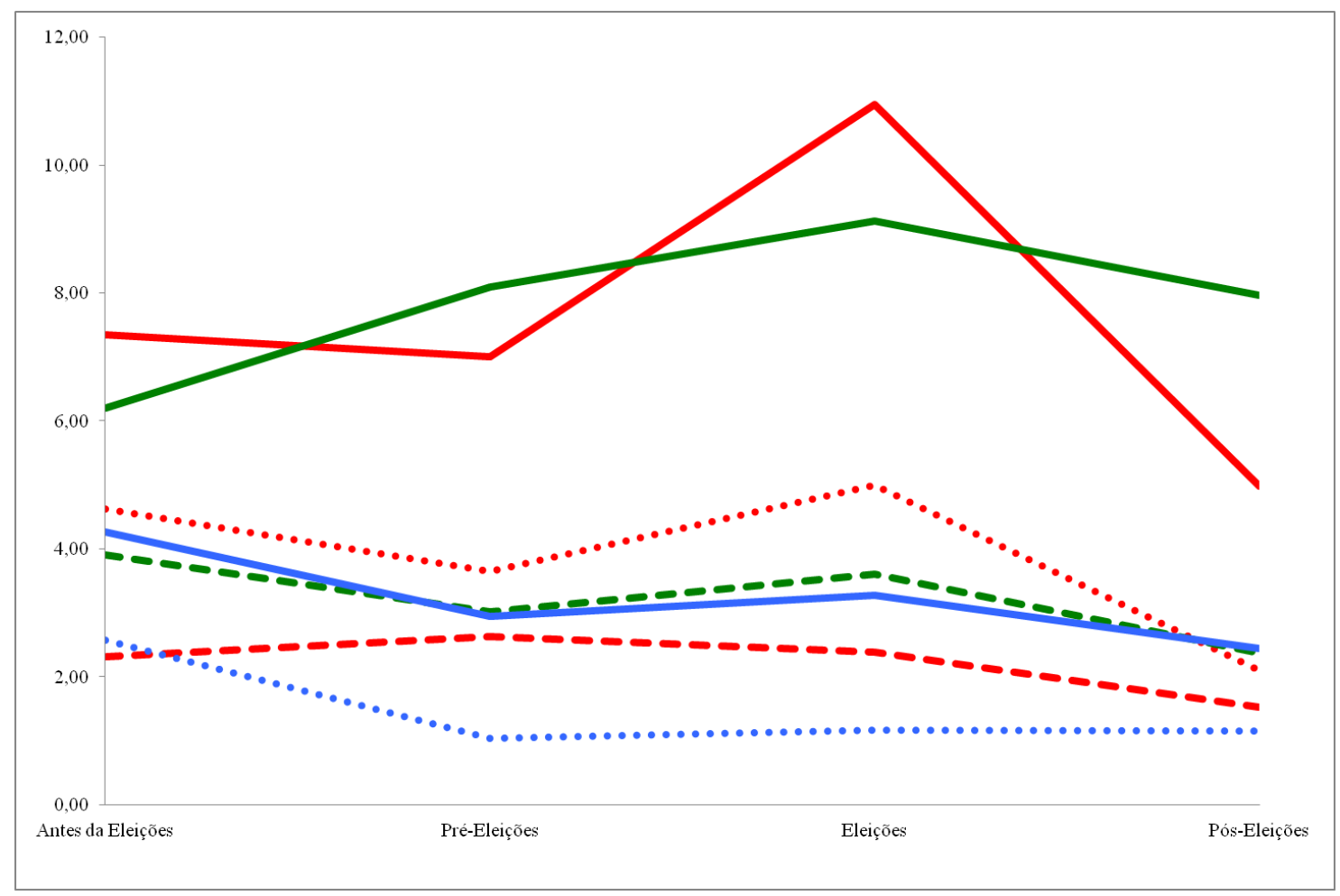

Senadores candidatos que permaneceram

Candidatos que trocaram de cargo

Candidatos que saíram ...........

Candidatos reeleitos $--\infty-0$

Senadores não candidatos que permaneceram

Candidatos não reeleitos $-0-0-0$

Não candidatos que saíram $\ldots \ldots \ldots$.......

Figura 3. Evolução do Ritmo de Postagem dos Grupos por Status Eleitoral Dados coletados entre 20 de dezembro de 2013 e 30 de abril de 2015. Fonte: Elaborada pelo autor.

No período pré-eleições, entre dezembro de 2013 e julho de 2014, a maioria dos grupos diminuiu o ritmo de postagem em relação ao momento anterior, enquanto, no período eleitoral, quase todos os grupos apresentaram um aumento na média diária de postagem. Os parlamentares não candidatos foram aqueles que, em média, menos utilizaram o Twitter para postar mensagens antes, durante e após as eleições, permanecendo com nível de atividade praticamente inalterado, indicando indiferença, desinteresse político em participar ou publicar informações no Twitter, alheios ao processo eleitoral. 
Os perfis dos usuários do Twitter exibem duas imagens: uma menor, com a foto do perfil, que contém uma imagem de identificação pessoal do usuário; e outra maior, como foto de capa, apresentada pelos usuários como pôsteres para exibir imagens de pessoas, lugares, objetos etc. Muitos políticos, além de postarem mensagens e compartilharem informações em seus perfis, alteraram também essas imagens para dar evidência a suas pretensões eleitorais. Esse uso do Twitter como panfleto eletrônico, explicitando números de candidatura e slogans da campanha eleitoral, indica o interesse dos congressistas em formar imagem política através da internet. No momento da coleta da terceira etapa, todos os perfis dos parlamentares no Twitter foram visitados e foi registrado o uso ou não do Twitter como panfleto eletrônico (Tabela 4). Dentre os 261 deputados reeleitos e com conta nessa rede à época das eleições, metade deles utilizou imagens de panfleto eletrônico.

Tabela 4

Uso do Twitter pelos Deputados no Período Eleitoral, por Resultado Eleitoral e Panfleto Eletrônico

\begin{tabular}{lllll}
\hline \multirow{2}{*}{ Indicadores de uso do Twitter } & \multicolumn{2}{l}{ Deputados Reeleitos } & \multicolumn{2}{l}{ Deputados Não Reeleitos } \\
\cline { 2 - 5 } & $\begin{array}{l}\text { Com Panfleto } \\
(\mathrm{N}=137)\end{array}$ & $\begin{array}{l}\text { Sem Panfleto } \\
(\mathrm{N}=124)\end{array}$ & $\begin{array}{l}\text { Com Panfleto } \\
(\mathrm{N}=38)\end{array}$ & $\begin{array}{l}\text { Sem Panfleto } \\
(\mathrm{N}=72)\end{array}$ \\
\hline Votos obtidos em 2014 & 125.558 & 116.865 & 45.230 & 48.464 \\
\hline Total de seguidores & 12.081 & 6.974 & 5.322 & $2.744^{*}$ \\
\hline Total de mensagens postadas & $7.814^{* *}$ & 3.939 & $7.850^{* *}$ & 2.212 \\
\hline Média diária de postagem & $5,08^{* *}$ & 1,94 & $6,05^{*}$ & 2,24 \\
\hline Última postagem (em Dias) & 8,2 & $276,4^{* *}$ & 86,1 & $307,2^{*}$ \\
\hline Total de contas seguidas & $1.498^{*}$ & 922 & $2.020^{*}$ & 703 \\
\hline $\begin{array}{l}\text { Crescimento no número de } \\
\text { seguidores }\end{array}$ & $8,23 \%$ & $3,26 \%$ & $3,75 \% *$ & $2,10 \%$ \\
\hline
\end{tabular}

Nota. Dados coletados em 30/09/2014. Fonte: Elaborada pelo autor.

O símbolo * indica que a variável é significante a $5 \%(\mathrm{p}<0,05)$, e **, a $1 \%(\mathrm{p}<0,01)$.

Conforme a Tabela 4, a média de votos obtidos nas eleições de 2014 dos Deputados reeleitos e cujas contas foram usadas como panfleto eletrônico foi praticamente a mesma daqueles que não adotaram essa prática, mas a média da taxa de crescimento no número de seguidores das contas com panfleto eletrônico foi duas vezes e meia superior à do segundo grupo. Uma das explicações para essa diferença pode estar no nível de atividades das contas, medido pela média diária de postagem no Twitter durante os dois meses do período eleitoral.

A média de postagem das contas com panfleto eletrônico no período eleitoral foi de 5,08 mensagens por dia, ou mais de duas vezes e meia a média das contas sem panfleto eletrônico, que foi de 1,94 mensagens diárias, mostrando que o esforço da campanha eleitoral online não se restringiu à divulgação do número do candidato na página do Twitter, mas também a uma presença mais ativa do político nessa rede e mostrando novamente que o aumento no nível de atividade tem relação positiva com o acréscimo de popularidade das contas na rede social. Comparando também as médias dos políticos não reeleitos que usam ou não panfletos eletrônicos em seus perfis, observa-se um maior crescimento no número de seguidores e na média diária de postagens no grupo de contas que usaram o panfleto eleitoral. As médias dos totais de contas seguidas também foram maiores para as contas que foram utilizadas como panfleto eletrônico.

A quantidade de dias da última postagem de um perfil é um indicativo da atividade ou do abandono dessa conta por seu usuário no Twitter. No grupo dos políticos que não utilizaram o Twitter como panfleto eletrônico, o valor elevado da média de dias da última postagem das contas em comparação com a média do segundo grupo indica que os políticos deste grupo demonstraram menor interesse em utilizar esta mídia no período eleitoral. 
A Figura 4 ilustra a variação no nível de popularidade dos grupos de análise da Tabela 4 e demonstra que os políticos mais ativos no Twitter durante as eleições obtiveram um crescimento maior no número dos seguidores de suas contas na rede. Os parlamentares reeleitos apresentam maior popularidade do que aqueles não reeleitos, sendo que aqueles não reeleitos e que fizeram uso de panfleto eletrônico praticamente mantiveram seus níveis de popularidade, como atesta o baixo percentual de crescimento no número de seguidores.

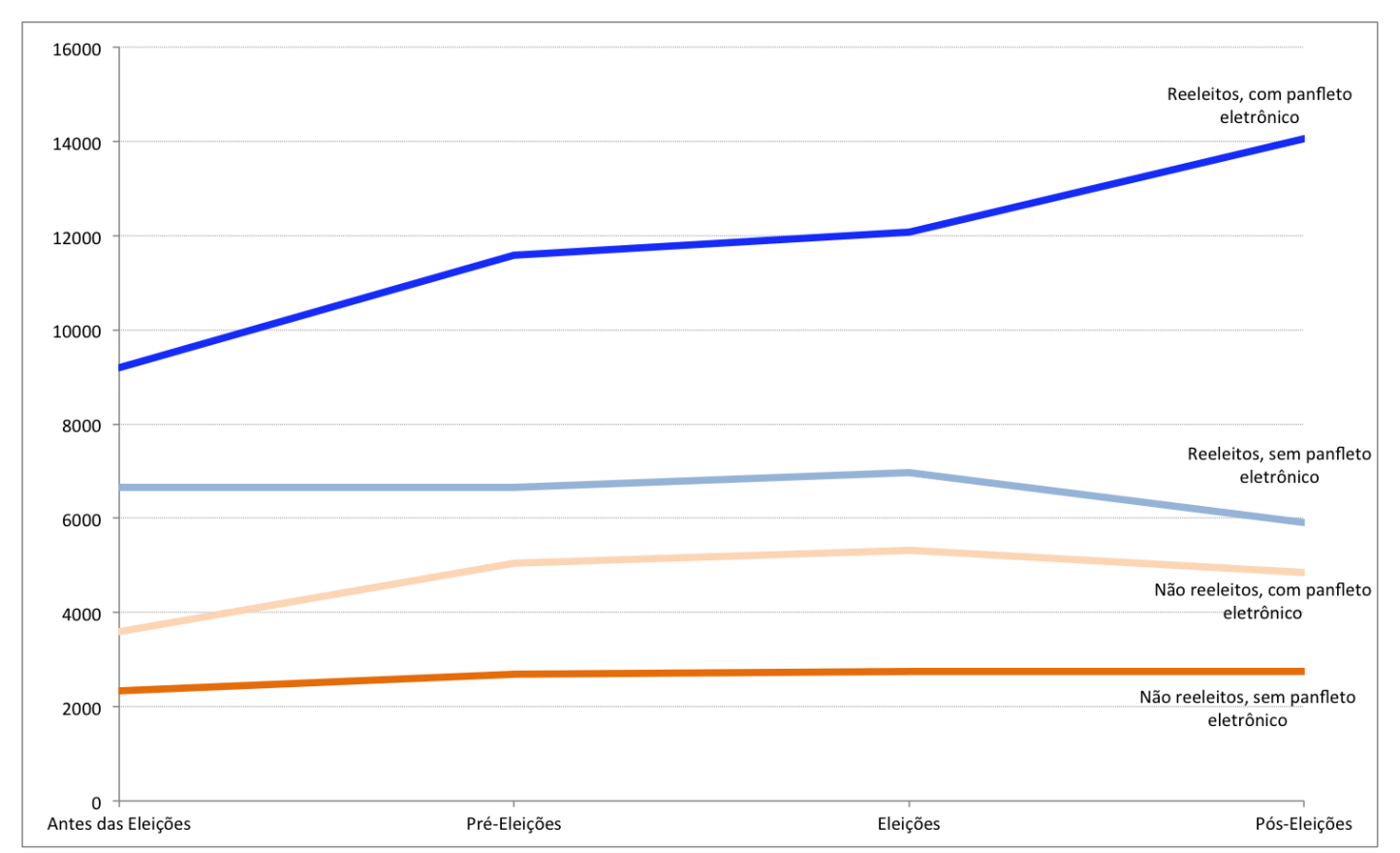

Figura 4. Variação na Média de Seguidores dos Deputados entre dezembro de 2013 e abril de 2015 Dados coletados entre 20 de dezembro de 2013 e 30 de abril de 2015. Fonte: elaborada pelo autor.

O uso do Twitter como panfleto eletrônico e sua relação com o ritmo de publicações de mensagens indicam o esforço dos políticos para conquistar a atenção dos internautas e, em períodos de eleição, os votos dos eleitores. Pelos dados apresentados, com esse esforço adicional no período eleitoral, os políticos que demonstraram maior atividade no uso da rede de fato obtiveram sucesso em atrair a atenção dos internautas, conforme indica o percentual de crescimento do número de seguidores de suas contas. Essa relação pode ser visualizada na Figura 4, que descreve a evolução dos valores das médias de seguidores dos Deputados nas quatro etapas da pesquisa, na Figura 5, que descreve a evolução das médias diárias de postagens dos Deputados, para os quatro grupos da Tabela 4. Pela Figura 4, observase o maior crescimento na média de seguidores dos perfis dos Deputados que fizeram uso do Twitter como panfleto eletrônico e que foram reeleitos, enquanto que a média de seguidores do grupo de políticos que não usaram o Twitter como panfleto eletrônico e que não foram reeleitos ficou praticamente estável durante as quatro etapas de análise.

A Figura 5 apresenta o ritmo de postagem diária pelos mesmos grupos analisados na figura anterior. Pela comparação da evolução das médias de postagem dos quatro grupos, os dados indicam que o ritmo de atividade explica o volume de atenção obtido e expresso pela quantidade de seguidores desses perfis no Twitter, com exceção do grupo de políticos não reeleitos que fizeram uso do Twitter como panfleto eletrônico. Para esses 38 Deputados, o esforço em aparecer no ambiente virtual não resultou em acréscimo no número de seguidores. 


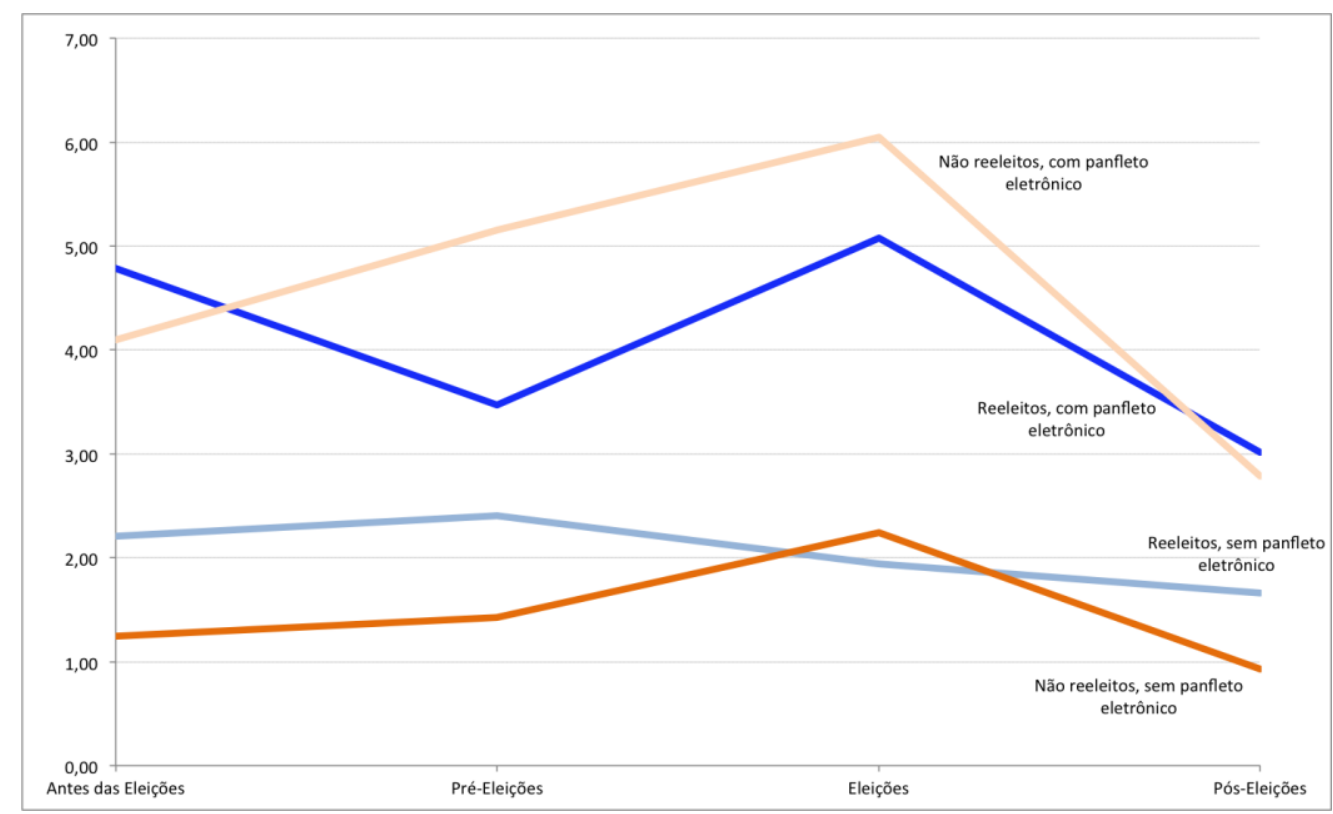

Figura 5. Evolução das Médias Diárias de Postagem das Contas dos Deputados entre dezembro de 2013 e abril de 2015

Dados coletados entre 20 de dezembro de 2013 e 30 de abril de 2015. Fonte: Elaborada pelo autor.

Analisando um outro aspecto do comportamento dos políticos durante o período eleitoral, a Tabela 5 relaciona os dados de utilização do Twitter para os dois grupos de parlamentares que não se candidataram a qualquer cargo eletivo em 2014. O primeiro grupo compreende os parlamentares que optaram por se afastar da política em 2014, enquanto o segundo grupo é composto pelos Senadores em meio de mandato que continuaram no Congresso após as eleições. Os indicadores de uso do Twitter repetem as diferenças apresentadas nas análises anteriores, ou seja, Senadores apresentam maior número total de seguidores, de mensagens postadas e de contas seguidas. A relação entre número de seguidores e total de mensagens postadas, no entanto, corrobora análises anteriores de que a popularidade dos perfis políticos no Twitter está diretamente relacionada ao ritmo de publicação de mensagens pelos parlamentares (Amaral, Pinho, Oliveira, \& Aguiar, 2014; Marques et al., 2014). No período eleitoral, os Senadores foram mais presentes em termos de postagem e, por isto, foram recompensados com um crescimento médio no número de seguidores de 2,97\%, enquanto o grupo de Deputados não candidatos perdeu seguidores.

Tabela 5

Indicadores de Uso do Twitter pelos Parlamentares Não Candidatos Durante as Eleições de 2014

\begin{tabular}{lll}
\hline Indicadores de uso do Twitter & \multicolumn{2}{l}{ Parlamentares Não Candidatos } \\
\cline { 2 - 3 } & $\begin{array}{l}\text { Deputados que saíram do } \\
\text { Congresso (N = 72) }\end{array}$ & $\begin{array}{l}\text { Senadores que permaneceram } \\
\text { no Congresso (N = 35) }\end{array}$ \\
\hline Média de seguidores & 7.438 & 30.121 \\
\hline Média de mensagens postadas & 3.875 & $7.543 *$ \\
\hline Média diária de postagem & 0,95 & 2,89 \\
\hline Última postagem (em Dias) & $332,44 *$ & 70,34 \\
\hline Total de contas seguidas & 1.067 & $2.331^{*}$ \\
\hline Crescimento médio no número de seguidores & $-0,15 \%$ & $2,97 \%$ \\
\hline
\end{tabular}

Nota. Dados coletados em 30/09/2014. Fonte: Elaborada pelo autor.

O símbolo * indica que a variável é significante a $5 \%(\mathrm{p}<0,05), \mathrm{e}^{* *}$, a $1 \%(\mathrm{p}<0,01)$. 
Comparados com os indicadores gerais de uso do Twitter nas análises anteriores, os valores da Tabela 5 mostram que os parlamentares não candidatos utilizaram o Twitter abaixo da média observada para o conjunto dos dados durante as eleições. Os indicadores de uso do Twitter pelos Senadores em meio de mandato, porém, aproximam-se das médias de uso do Twitter, o que indica que os congressistas em meio de mandato usam a rede social de forma distinta daqueles que estão em vias de se afastar do exercício parlamentar. Enquanto os primeiros representam parlamentares em pleno exercício de seus mandatos, os últimos demonstram indiferença em participar das discussões no meio digital.

Esses dados confirmam que o uso da rede social durante as eleições depende das intenções políticas dos parlamentares em relação ao pleito eleitoral. Quando há o interesse imediato em ter visibilidade e atrair a atenção do público, o político aumenta sua participação no ambiente virtual. Porém, quando não há pretensões eleitorais, cai consideravelmente o esforço de comunicação no meio digital. E, no meio termo, quando não há participação no pleito eleitoral, mas o parlamentar segue com suas funções políticas e mantém seus canais de comunicação abertos, como no caso dos Senadores em meio de mandato, seus indicadores de uso do Twitter apontam para um meio termo entre os políticos em meio aos esforços da disputa eleitoral e a indiferença dos políticos que estão alheios a esse processo.

As análises do uso do Twitter durante o período eleitoral apontam para um quadro de pragmatismo político: quando o político não tem pretensões eleitorais, então ele não tem interesse em aparecer no meio digital, nem postar mensagens nem interagir. Quando está em campanha eleitoral, os políticos não somente participam, como aumentam o ritmo de postagem, seguem mais outras contas e buscam aumentar seu número de seguidores. E, no meio termo, quando o político está em atividade, mas não em campanha eleitoral, como os Senadores em meio de mandato, então seu uso da mídia permanece inalterado durante o período eleitoral - nem aumenta, nem diminui. Ainda que, com esses dados, não seja possível estabelecer relação direta entre o uso do Twitter e o resultado eleitoral, é possível afirmarse que os políticos têm atribuído importância eleitoral significativa e têm investido nessa mídia.

O pragmatismo dos políticos em utilizar o Twitter durante as campanhas eleitorais tem um propósito: a obtenção de votos dos eleitores. Neste sentido, cabe agora avaliar se a visibilidade obtida pelos parlamentares no Twitter - avaliada aqui pelo número de seguidores de seu perfil - tem alguma relação com o resultado obtidos por eles nas eleições - medido aqui pela quantidade de votos recebidos nas eleições de 2014. Para todo o conjunto de dados, ou seja, para todos os políticos com conta no Twitter em setembro de 2014, a relação é estatisticamente relevante: quanto maior o número de seguidores de um parlamentar no Twitter, maior a quantidade de votos obtidos por ele no pleito (Corr. Spearman $=0,369 ; \alpha=0,01)$. Excluindo Senadores, que concorrem a eleições majoritárias e cujos suplentes não recebem votos, a relação entre popularidade dos Deputados candidatos à reeleição em setembro de 2014 e os votos obtidos por eles se mantém significante: quanto mais popular o Deputado, mais votos obteve (Corr. Spearman $=0,271 ; \alpha=0,01)$.

Mesmo para os novos Deputados, a relação é estatisticamente significante: quanto mais votos o novo Deputado obteve em 2014, maior sua popularidade no Twitter, medida pelo número de seus seguidores em abril de 2015 (Corr. Spearman $=0,231 ; \alpha=0,01$ ). A relação entre popularidade no Twitter e quantidade de votos obtidos é forte também dentro do grupo de parlamentares reeleitos: quanto mais populares eles eram à época das eleições, mais votos obtiveram no pleito (Corr. Spearman $=0,270 ; \alpha=$ $0,01)$. Ainda que sejam excluídos os Senadores desta análise, a relação se mantém forte (Corr. Spearman $=0,262 ; \alpha=0,01)$.

\section{Conclusões}

Retomando então o problema proposto, que foi descrever como os parlamentares, dadas suas pretensões políticas, utilizaram o Twitter durante as eleições de 2014, e como essa utilização resultou em resultado eleitoral, os dados indicam que os políticos aderiram ao Twitter em um movimento quase sincronizado, principalmente em períodos pré-eleitorais. O movimento de adesão dos parlamentares 
indica que eles reagiram aos sinais positivos obtidos pelos primeiros usuários, conforme apontado por Chi e Yang (2011). Às vésperas das eleições, os parlamentares tendem a aumentar suas presenças na rede, postando mais conteúdos e buscando visibilidade para suas campanhas eleitorais, obtendo, com isso, mais popularidade e, com ela, mais votos.

A pesquisa realizada atestou que há três perfis de comportamento bem delimitados na análise dos dados desta pesquisa: o comportamento dos políticos com pretensões eleitorais; o comportamento dos que estavam em exercício regular de seus mandatos; e o comportamento daqueles que estavam em vias de se afastar da atividade política (ainda que apenas no curto prazo). O primeiro grupo se esforçou em aparecer no ambiente virtual e obteve mais atenção; o terceiro grupo se mostrou alheio ao processo eleitoral e igualmente alheio ao uso das redes sociais; e o segundo grupo representou o meio-termo nessa escala. A atividade dos eleitores já havia predito o resultado de eleições (Tumasjan et al., 2010), e a popularidade das contas parlamentares no Twitter já apresentava relação com a quantidade de votos obtidos por eles nas últimas eleições (Amaral et al., 2014). Nesse estudo, foi possível compreender que os políticos em campanha conheciam essas relações e fizeram investimentos eleitorais nesse sentido, obtendo, em média, resultados melhores que seus concorrentes.

No mesmo sentido do personalismo e do apelo à subjetividade observados na campanha de 2010 (Pereira, 2013), o grupo dos parlamentares candidatos utilizaram o Twitter para promoção direta de suas campanhas eleitorais, com a divulgação de número de campanha e/ou slogan político. Esse subgrupo é ainda mais ativo no Twitter, tendo obtido com isso um maior crescimento em sua popularidade virtual. Já no grupo dos não candidatos, os Senadores em meio de mandato mantiveram suas presenças e atividades no ambiente virtual, enquanto os Deputados em fim de mandato diferenciaram-se desse grupo tanto em ritmo de postagem quanto no crescimento de popularidade no Twitter.

Os dados apontam para uma apropriação pragmática do Twitter por parte dos parlamentares, sugerindo que o objetivo primeiro do uso dessa tecnologia é a obtenção de votos. Neste sentido e a partir dos indicadores de popularidade virtual e da quantidade de votos obtidos no processo eleitoral, os políticos empenhados no ambiente virtual estão alcançando seus objetivos. Ainda que a relação estatística observada aqui entre popularidade e votos seja essa - políticos mais populares no Twitter obtêm maior quantidade de votos nas eleições - ou ter sentido inverso - políticos com maior visibilidade política (mais bem votados) obtêm maior popularidade no Twitter, é importante observar que o comportamento dos parlamentares brasileiros indica a compreensão dessa relação, quando mantêm ou aumentam suas presenças no ambiente virtual, especialmente durante as eleições.

Embora o uso das novas redes sociais não seja imprescindível para o sucesso eleitoral dadas as outras variáveis relacionadas às regras eleitorais, por exemplo, os dados indicam que o uso do Twitter tiveram relação com o desempenho dos parlamentares nas eleições de 2014. Este é um trabalho circunscrito a um período eleitoral e a um objeto empírico e são conclusões iniciais, mas apontam para a necessidade de maiores investigações sobre a relação entre o ambiente virtual e o processo eleitoral, especialmente considerando a velocidade das mudanças na política brasileira e no meio digital.

Os níveis de participação política pelos parlamentares no Twitter podem ser entendidos até como surpreendentes, considerando-se a questão da apatia ou da passividade da sociedade brasileira (Oliveira, Catapan, \& Vicentín, 2015). Porém, é necessário esperar a análise de outros eventos, outras rodadas de eleições, para se verificar se o uso das redes sociais é uma tendência permanente ou se é novidade passageira que desperta atenção e interesse. Pesquisas futuras podem identificar se todo esse movimento de uma participação intensa dos políticos através do Twitter não representa uma elitização da participação política restrita àqueles que manuseiam com mais habilidade os dispositivos tecnológicos. O período eleitoral de 2018, por exemplo, pode confirmar e/ou esclarecer melhor os achados deste trabalho, assim como pesquisas que avaliem o teor das mensagens postadas e as interações realizadas pelos políticos podem delimitar mais o comportamento dos políticos no ambiente virtual. 


\title{
Notas
}

\begin{abstract}
${ }^{1}$ Apesar desse limite de caracteres ter sido vigente no período analisado nesse trabalho, recentemente o Twitter iniciou um período de teste com novo limite de 280 caracteres para cada mensagem (Recuperado em 28 outubro, 2017 de blog.Twitter.com/official/en_us/topics/product/2017/Giving-you-more-characters-to-express-yourself.html).

${ }^{2}$ Foram consideradas contas inativas todos os perfis que, na data da coleta de dados, não havia postado qualquer mensagem nos últimos 30 dias.
\end{abstract}

\section{Material Suplementar}

Todos os dados e materiais foram disponibilizados publicamente por meio da plataforma Mendeley e podem ser acessados em: Amaral, Marcelo; Pinho, José Antonio (2018), "Data for: " Parliamentary Elections in Brazil: The Use of Twitter in the Search for Votes" published by RAC - Revista de Administração Contemporânea", Mendeley Data, v1 http://dx.doi.org/10.17632/7b3vp6bz9p.1

\section{Contribuições}

$1^{\circ}$ autor: Elaborou o modelo de análise, construiu as referências teóricas, coletou e analisou os dados, redigiu outras seções do trabalho e formatou a versão final do texto.

$2^{\circ}$ autor: Contribuiu com a construção do referencial teórico, com as inferências das análises e com a redação de outras seções do trabalho, além de revisar as versões do texto.

\section{Referências}

Amaral, M. S., \& Pinho, J. A. G. (2015, setembro). Ideologias partidárias em 140 caracteres: Adoção e uso do Twitter pelo Congresso Brasileiro. Anais do Encontro Nacional da Associação Nacional de Pós-Graduação e Pesquisa em Administração, Belo Horizonte, MG, Brasil, 39.

Amaral, M. S., Pinho, J. A. G., Oliveira, L. S., \& Aguiar, I. S. (2014, setembro). O Congresso nas redes sociais: Uso do Twitter por parlamentares brasileiros. Anais do Encontro Nacional da Associação Nacional de Pós-Graduação e Pesquisa em Administração, Rio de Janeiro, RJ, Brasil, 38.

Braga, S., \& Cruz, L. C. (2012). Elites parlamentares e novas tecnologias: Um estudo sobre o uso da internet pelos deputados estaduais brasileiros da $16^{a}$ legislatura (2007-2011) [Texto para discussão, $n^{\circ}$ 4]. Curitiba, PR: UFPR.

Cha, M., Haddadi, H., Benevenuto, F., \& Gummadi, K. P. (2010). Measuring user influence in Twitter: The million follower fallacy. Proceedings of the International AAAI Conference on Web and Social Media, Washington, DC, USA, 4.

Chi, F., \& Yang, N. (2011). Twitter adoption in Congress. Review of Network Economics, 10(1). http://dx.doi.org/10.2202/1446-9022.1255

Costa, C. T. (2011, abril 13). O papel da internet na conquista dos votos de Marina Silva. Revista Interesse Nacional, 4(13), 59-75.

Golbeck, J., Grimes, J., \& Rogers, A. (2010). Twitter use by the U.S. Congress. Journal of the American Society for Information Science and Technology, 61(8), 1612-1621. http://dx.doi.org/10.1002/asi.21344 
Gomes, W., Fernandes, B., Reis, L., \& Silva, T. (2009). "POLITICS 2.0": A campanha on-line de Barack Obama em 2008. Encontro da Compós, Belo Horizonte, MG, Brasil, 18.

Hemphill, L., Otterbacher, J., \& Shapiro, M. (2013). What's congress doing on Twitter? Proceedings of the Conference on Computer Supported Cooperative Work, San Antonio, TX, USA. Retrieved 3 April, 2014, from http://dl.acm.org/citation.cfm?id=2441876

Java, A., Finin, T., Song, X., \& Tseng, B. (2007). Why we Twitter: Understanding microblogging usage and communities. Webkdd and Sna-Kdd 2007 Workshop on Web Mining and Social Network Analysis, San Jose, CA, USA, 9. Retrieved 8 August, 2013, from http://dl.acm.org/citation.cfm?id=1348556

Mainwaring, S. P. (2001). Sistemas partidários em novas democracias: O caso do Brasil (V. Pereira, Trad.). Rio de Janeiro: Editora FGV. (Obra original publicada em 2001)

Marques, F. P. J. A., Aquino, J. A., \& Miola, E. (2014). Congressmen in the age of social network sites: Brazilian representatives and Twitter use. First Monday, 19(5). Chicago, IL, USA. Retrieved 12 May, 2014, from http://firstmonday.org/ojs/index.php/fm/article/view/5022

Marques, F. P. J. A., \& Sampaio, R. C. (2011). Internet e eleições 2010 no Brasil: Rupturas e continuidades nos padrões mediáticos das campanhas políticas online. Revista Galáxia, (22), 208221.

Nogueira, M. A. (1998). As possibilidades da política: Idéias para uma reforma democrática do Estado. São Paulo: Paz e Terra.

Oliveira, A. G. de, Catapan, A., \& Vicentín, I. C. (2015). A apatia da participação política do povo brasileiro na administração e governança da república: Motivos e consequências. Revista de Globalización, Competitividad y Gobernabilidad, 9(2), 108-123. Recuperado em 17 outubro, 2017 de https://gcg.universia.net/article/view/1155

Pereira, N. B. (2013). Sob o piado do Twitter: O novo tom das campanhas eleitorais com a difusão da internet no Brasil (Dissertação de mestrado). Curso de Mestrado em Ciências Sociais, Pontifícia Universidade Católica de São Paulo, São Paulo, SP, Brasil.

Pinho, J. A. G. (2016). Reforma da administração pública no Brasil: A resistência do "bunker" patrimonialista e a reforma que não acontece. Revista Sociedade, Contabilidade e Gestão, 3(11), 130-140. http://dx.doi.org/10.21446/scg_ufrj.v11i3.13392

Reis, P. H. S. (2011). Novas formas de campanha política: O uso das NTIC's nas eleições de 2010 - o caso Marina Silva. Revista Pensata, 1(1), 44-64.

Teixeira, M. A. C. (2004). Negociação política e as formas de interação Executivo Legislativo no Brasil no período de 1983 a 1992. Cadernos Gestão Pública e Cidadania, 9(40). http://dx.doi.org/10.12660/cgpc.v9n40.44024

Tumasjan, A., Sprenger, T. O., Sandner, P. G., \& Welpe, I. M. (2010). Predicting elections with Twitter: What 140 characters reveal about political sentiment. Proceedings of the International AAAI Conference on Weblogs and Social Media, Washington, DC, USA, 4.

Vergeer, M., Hermans, L., \& Sams, S. (2013). Online social networks and micro- blogging in political campaigning: The exploration of a new tool and a new campaign style. Party Politics, 19(3), 477501. http://dx.doi.org/10.1177/1354068811407580

Williams, J. A., \& Spiro, E. S. (2015). Tweeting the Japanese general election of 2014 - A first look [Working Paper]. University of Washington Workshop on "Voting, Elections, and Electoral Systems", Washington, DC, USA. 


\section{Dados dos Autores}

Marcelo Santos Amaral

Estrada do Bem-Querer, Km 04, 45083-900, Vitoria da Conquista, BA, Brasil. E-mail: marcelo.amaral@uesb.edu.br. http://orcid.org/0000-0001-7639-4059

José Antonio Gomes de Pinho

Av. Reitor Miguel Calmon, s/n, 40110-060, Vale do Canela, Salvador, BA, Brasil. E-mail: jagp@ufba.br. https://orcid.org/0000-0002-4122-3652 